\title{
Salt intake in 3-year-old Japanese children
}

\author{
Yuki Morinaga ${ }^{1}$, Takuya Tsuchihashi ${ }^{1}$, Yuko Ohta $^{1}$ and Kiyoshi Matsumura ${ }^{2}$
}

Salt restriction is widely recommended for the prevention and management of hypertension. It is very important to reduce salt intake during childhood. This survey was conducted to investigate salt intake in Japanese children. The study subjects, totalling 1424, comprised 3-year-old children who received health checkups conducted by a public health center. Using first-morning urine samples, urinary concentrations of sodium, potassium and creatinine were measured. Additionally, the participants' parents filled out a questionnaire regarding their children's dietary habits. Urinary sodium and potassium concentrations were $140 \pm 67$ and $67 \pm 41 \mathrm{mmol} \mathrm{I}^{-1}$, respectively. The estimated urinary sodium excretion values had a wide distribution, with a mean value of $75 \pm 47 \mathrm{mmol}$ per day (4.4 g per day of salt). Sodium excretion exceeded 100 and $200 \mathrm{mmol}$ per day in 336 ( $24 \%$ ) and $32(2.2 \%)$ subjects, respectively. Urinary sodium excretion was significantly higher in children who had older siblings than in firstborn children ( $78 \pm 49$ vs. $72 \pm 45 \mathrm{mmol}$ per day, $P<0.05)$. The urinary sodium/potassium ratio was also higher in the former group $(3.0 \pm 2.7$ vs. $2.7 \pm 2.2, P<0.01)$. Sodium excretion tended to be higher in children who ate daily snacks than in those who did not (76 \pm 48 vs. $71 \pm 44 \mathrm{mmol}$ per day, $P=\mathbf{0 . 0 7}$ ). In contrast, potassium excretion was significantly higher and the sodium/potassium ratio was lower in children who ate fruits daily than those who did not ( $39 \pm 29 \mathrm{vs}$. $33 \pm 23 \mathrm{mmol}$ per day and $2.6 \pm 2.0$ vs. $3.2 \pm 2.7, P<0.01$, respectively). These results suggest that excess salt intake occurs in a significant number of 3-year-old Japanese children. The presence of older siblings and dietary habits of eating snacks or fruits influence their sodium and potassium intake.

Hypertension Research (2011) 34, 836-839; doi:10.1038/hr.2011.55; published online 19 May 2011

Keywords: children; salt intake; sodium/potassium ratio

\section{INTRODUCTION}

Many epidemiological studies have shown that excess salt intake contributes to the development of hypertension. ${ }^{1-4}$ In addition, a high-salt diet is reported to have direct harmful effects; for example, it increases the risk of stroke, renal disease and cardiovascular disease, independently of blood pressure elevation. ${ }^{5,6}$ Moreover, a relationship between salt intake and stomach cancer has also been suggested. ${ }^{7,8}$ Therefore, a reduction in salt intake is an important issue for public health.

Although salt intake in Japan has decreased in recent years, a national survey showed that the average salt intake remains highup to $10.6 \mathrm{~g}$ per day in 2007.9 The Japanese guidelines for the management of hypertension (JSH 2009) recommend the reduction of salt intake to $<6 \mathrm{~g}$ per day in hypertensive patients. ${ }^{10}$ In our previous survey on hypertensive outpatients, this reduction in salt intake was not achieved even in patients who are conscious about salt restriction. ${ }^{11}$ Long-term compliance with salt restriction in hypertensive patients was also extremely low. ${ }^{12}$ As it is difficult to change dietary habits in adults, education or intervention to reduce salt intake during childhood is very important. However, there are very few studies addressing salt intake in Japanese children. Therefore, this study was conducted to investigate salt intake in 3-year-old Japanese children and to examine the lifestyle characteristics associated with salt intake.

\section{METHODS}

The subjects were 3-year-old children who attended health checkups conducted by the Sawara public health center, Fukuoka City, Japan, from June 2008 to March 2009. On the day of the checkup, subjects collected their first-morning urine samples at home and brought the samples to the center. The aim and detailed procedures of this survey were explained to the parents, and written informed consent was obtained from them. Then, we asked the parents to fill out a questionnaire regarding their children's dietary habits, focusing especially on the frequency of eating snacks and fruits. The presence of older siblings and the parents' awareness about reducing salt intake were also investigated.

A total of 1679 children participated in the health checkup during the survey period. Among them, 1424 participants provided both the written informed consent and a urine sample with enough volume to analyze. Body height and weight were measured by nurses, and the body mass index (weight $(\mathrm{kg}) /$ height $(\mathrm{m})^{2}$ ) was calculated.

Using their first-morning urine samples, urinary concentrations of sodium, potassium and creatinine were measured. The 24-h urine volume of 3- to 5 -year-old healthy Japanese children with a mean body weight of $17.4 \mathrm{~kg}$ was reported as $533 \pm 185 \mathrm{ml}$ per day or $31 \pm 11 \mathrm{ml} \mathrm{kg}^{-1} .{ }^{13}$ As the mean body weight of the participants of the present study was $13.7 \mathrm{~kg}$, we assumed the urine volume of 3-year-old children to be $500 \mathrm{ml}$ per day. Based on the

${ }^{1}$ Division of Hypertension, Clinical Research Institute, National Kyushu Medical Center, Fukuoka, Japan and ${ }^{2}$ Department of Medicine and Clinical Science, Kyushu University Graduate School of Medical Sciences, Fukuoka, Japan

Correspondence: Dr T Tsuchihashi, Division of Hypertension, Clinical Research Institute, National Kyushu Medical Center, Jigyohama 1-8-1, Chuo-ku, Fukuoka 810-8563, Japan.

E-mail: tuti@kyumed.jp

Received 5 December 2010; revised 16 January 2011; accepted 6 February 2011; published online 19 May 2011 
present finding that the average urinary creatinine concentration was $67.9 \pm 33.3 \mathrm{mg} \mathrm{dl}^{-1}$, we also assumed that the urinary creatinine excretion was approximately $300 \mathrm{mg}$ per day, and thus, daily urinary sodium excretion was expressed as mmol per $300 \mathrm{mg} \mathrm{Cr}$.

\section{Statistical analysis}

Results are shown as the mean \pm s.d. The differences in the variables were compared by one-way ANOVA. Categorical data were analyzed using the $\chi^{2}$-test. $P$ values $<0.05$ were considered statistically significant

\section{RESULTS}

The characteristics of the 1424 participants ( 745 boys and 679 girls) are presented in Table 1 . The mean body height and weight were $93.1 \pm 3.4 \mathrm{~cm}$ and $13.7 \pm 1.5 \mathrm{~kg}$, respectively. Among the participants, $734(52 \%)$ were firstborn children and $690(48 \%)$ had older siblings. The urinary sodium and potassium concentrations were $139.5 \pm 67.0$ and $66.6 \pm 41.3 \mathrm{mmoll}^{-1}$, respectively. There was a significant positive correlation between urinary sodium and potassium concentrations $(r=0.17, P<0.01$, Figure 1).

The mean value of urinary sodium excretion was estimated to be $75 \pm 47 \mathrm{mmol}$ per day $(4.4 \mathrm{~g}$ per day of salt). As shown in Figure 2, urinary sodium excretion levels had a wide distribution. Sodium excretion exceeded 100 and $200 \mathrm{mmol}$ per day in 336 (24\%) and 32 (2.2\%) subjects, respectively. Using the same methods, urinary potassium excretion was estimated to be $36 \pm 26 \mathrm{mmol}$ per day.

Figure 3 shows the comparison of urinary sodium excretion, sodium/potassium ratios and body mass indexes between firstborn children and those with older siblings. Urinary sodium excretion levels were significantly higher in children with older siblings than

\section{Table 1 Characteristics of participants}

\begin{tabular}{lc}
\hline$N$ & 1424 \\
Sex (boys/girls) & $745 / 679$ \\
Height $(\mathrm{cm})$ & $93.1 \pm 3.4(77.9-107.3)$ \\
Weight $(\mathrm{kg})$ & $13.7 \pm 1.5(9.2-22.6)$ \\
Body mass index $\left(\mathrm{kg} \mathrm{m}^{-2}\right)$ & $15.7 \pm 1.1(11.6-20.2)$ \\
Maternal age (years) & $33.7 \pm 4.5(20-47)$ \\
Firstborn (\%) & 52 \\
UCr (mg dI & \\
UNa $\left(\mathrm{mmol} \mathrm{I}^{-1}\right)$ & $67.9 \pm 33.3$ \\
UK (mmol I-1) & $139.5 \pm 67.0$ \\
\hline
\end{tabular}

Abbreviations: $\mathrm{UCr}$, urinary creatinine; UNa, urinary sodium; UK, urinary potassium. Values are means \pm s.d.

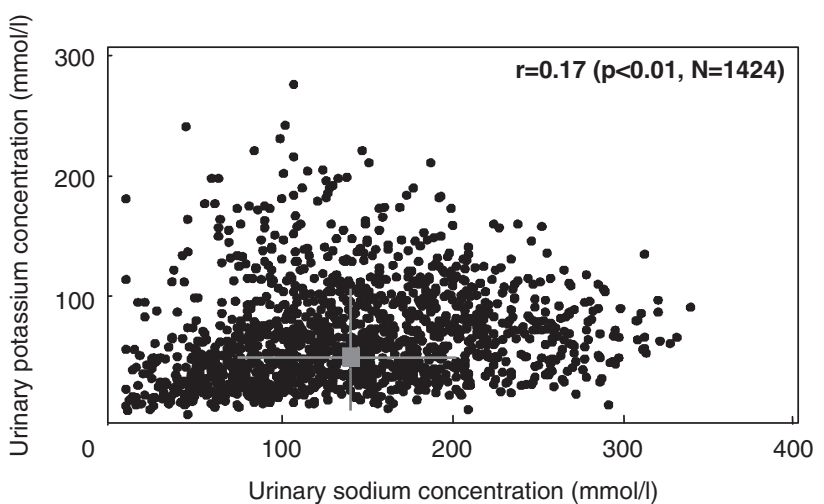

Figure 1 Relationship between urinary sodium and potassium concentrations. in firstborn children $(77.8 \pm 48.6$ vs. $72.1 \pm 44.7 \mathrm{mmol}$ per day, $P<0.05)$. The urinary sodium/potassium ratios were also significantly higher in children with older siblings $(3.0 \pm 2.7$ vs. $2.7 \pm 2.2, P<0.01)$. As shown in Figure 4, children who ate daily snacks compared with those who did not tended to have higher urinary sodium excretion levels $(76.3 \pm 47.6 \mathrm{mmol}$ per day, $n=1029$, vs. $71.2 \pm 44.3 \mathrm{mmol}$ per day, $n=386, P=0.069$ ) and significantly higher body mass indexes $\left(15.8 \pm 1.1\right.$ vs. $\left.15.6 \pm 1.1 \mathrm{~kg} \mathrm{~m}^{-2}, P<0.01\right)$. The prevalence of subjects who ate snacks daily was significantly $(P<0.01)$ higher in the children

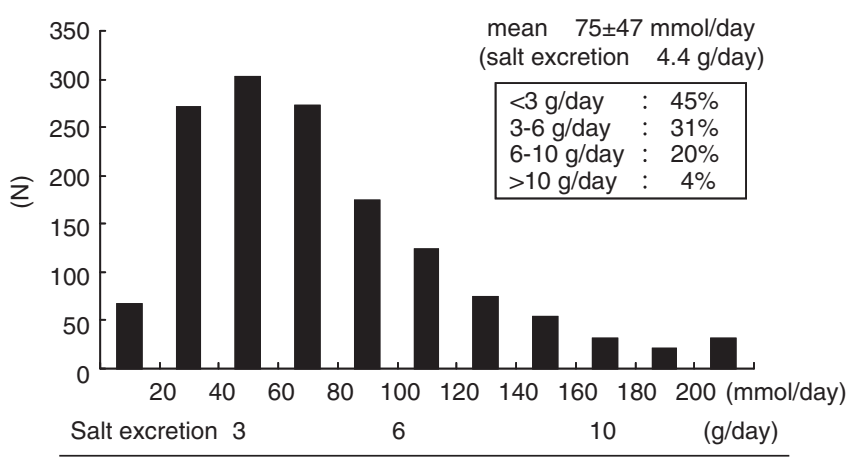

Figure 2 Distribution of estimated urinary sodium excretion (mmol per $300 \mathrm{mg}$ Cr).

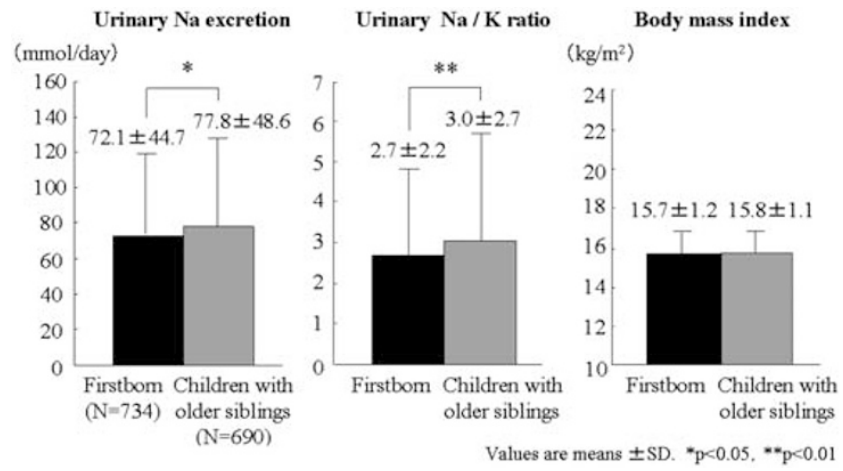

Figure 3 Comparison of urinary sodium excretion (left), urinary sodium $(\mathrm{Na}) /$ potassium (K) ratios (middle) and body mass indexes (right) between firstborn children and children with older siblings.

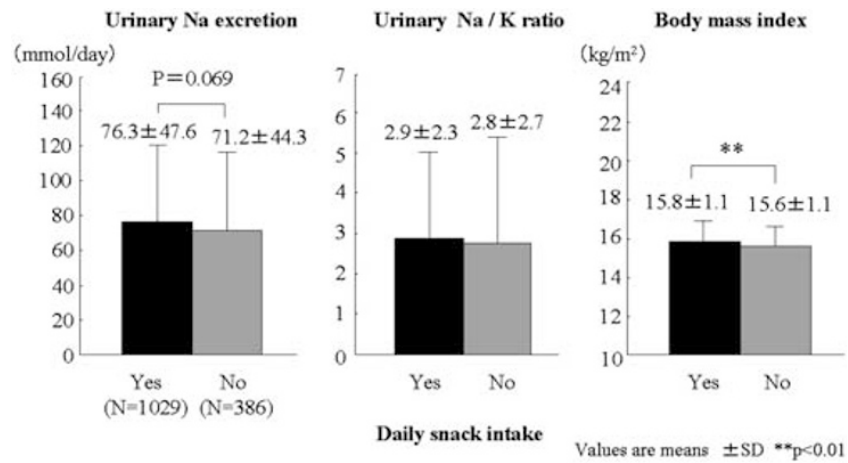

Figure 4 Comparison of urinary sodium excretion (left), urinary sodium ( $\mathrm{Na}$ )/ potassium ( $\mathrm{K}$ ) ratios (middle) and body mass indexes (right) between children who ate snacks daily and those who do not. 

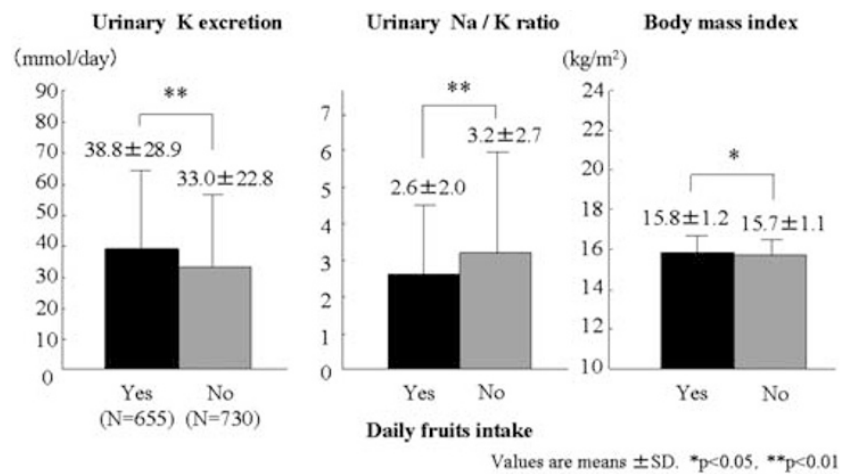

Figure 5 Comparison of urinary sodium excretion (left), urinary sodium $(\mathrm{Na})$ / potassium (K) ratios (middle) and body mass indexes (right) between the children who eat fruits daily and those who do not.

with older siblings (80\%) than that in firstborn children (66\%). Regarding fruit consumption, 655 participants ate fruits daily and the remaining 730 did not. Urinary potassium excretion was significantly higher and sodium/potassium ratios were significantly lower in children who ate fruits daily than in those who did not (Figure 5). The body mass indexes were also significantly higher in children who ate fruits daily. A total of $69 \%$ of mothers reported that they were conscious about salt restriction. The maternal age of the salt-conscious group was significantly higher than that of the non-salt-conscious group ( $34 \pm 4$ vs. $33 \pm 5$ years, $P<0.01$ ). Although the urinary sodium excretion levels did not differ between children with salt-conscious mothers and those with non-salt-conscious mothers $(74.4 \pm 46.6 \mathrm{vs}$. $75.4 \pm 46.2 \mathrm{mmol}$ per day, NS), the urinary potassium excretion levels were significantly higher for children with salt-conscious mothers than for children with non-salt-conscious mothers $(36.7 \pm 27.8 v s$. $33.5 \pm 21.3 \mathrm{mmol}$ per day, $P<0.05)$.

\section{DISCUSSION}

The major findings of the present study are that the mean salt intake of 3-year-old Japanese children is estimated to be $4.4 \mathrm{~g}$ per day and that a significant number of children seem to take in excessive amounts of salt. The presence of older siblings and dietary habits of eating daily snacks contribute to the increased salt intake, whereas eating fruits daily leads to an increase in urinary potassium excretion and a decrease in the sodium/potassium ratio.

It is well established that salt excess contributes to the development of hypertension, and thus, salt restrictions are widely recommended for the prevention and management of hypertension. ${ }^{1-4}$ As in adults, the positive relationship between salt intake and blood pressure has already been reported in children. ${ }^{14-19}$ A large cross-sectional study in Great Britain that investigated 1658 children and adolescents with a mean age of $11 \pm 0.1$ years showed a significant association of salt intake with systolic blood pressure (SBP). ${ }^{14}$ That study estimated that increasing salt intake by $1 \mathrm{~g}$ per day would relate to an SBP increase of $0.4 \mathrm{~mm} \mathrm{Hg}$. According to a recent meta-analysis of 10 salt-reduction trials in children and adolescents, a modest reduction in salt intake had a significant influence on blood pressure. ${ }^{15}$ With a $42 \%$ reduction in salt intake, which is equivalent to a decrease of approximately $3 \mathrm{~g}$ per day, SBP was reduced by $1.2 \mathrm{~mm} \mathrm{Hg}$ and diastolic blood pressure was reduced by $1.3 \mathrm{~mm} \mathrm{Hg}$. In addition, a well-controlled doubleblind study was conducted in 1980 among 476 Dutch newborn babies to study the effect of a low- or normal-sodium diet on blood pressure during the first 6 months of life. ${ }^{16}$ When salt intake was reduced by approximately $30 \%$, the SBP at the sixth month was $2.1 \mathrm{~mm} \mathrm{Hg}$ lower than that found in the usual salt group. Interestingly, 35\% of the babies were followed up 15 years later, and it was found that the reduced-salt group continued to have a lower SBP by $3.6 \mathrm{~mm} \mathrm{Hg}$ and a lower diastolic blood pressure by $2.2 \mathrm{~mm} \mathrm{Hg} .{ }^{17}$ This observation clearly indicates that exposure to salt early in life influences blood pressure later in life.

As salt intake in Japan is known to be traditionally high, it seems extremely important to make an effort to reduce salt intake. ${ }^{20}$ The difficulty in achieving dietary salt restrictions may be attributed partly to the difficulty in changing dietary habits formed during the early stages of childhood. Therefore, it seems important to develop appropriate dietary habits early in childhood. To our knowledge, few reports have investigated the salt intake of Japanese children. A national nutrition survey in 2007 reported that the average salt intake of 1to 6-year-old Japanese children was $6.1 \mathrm{~g}$ per day. ${ }^{9}$ The report Dietary Reference Intakes for the Japanese, 2010, issued by the Ministry of Health, Labor and Welfare, recommends that the salt intake for children should preferably be $<4 \mathrm{~g}$ per day for 1 - to 2 -year-old children and $<5$ g per day for 3 - to 5 -year-old children. ${ }^{21}$ In this study, $68.0 \%$ of the children were estimated to have a salt intake of $<5 \mathrm{~g}$ per day, and a significant number of them exceeded the adequate salt intake level.

In the present study, the presence of older siblings was associated with high salt intake. Salt intake was also significantly higher in children who ate daily snacks, which usually have a high content of salt, fat and sugar. The presence of older siblings seems to be associated with the dietary habit of eating daily snacks. In contrast, potassium intake was significantly higher in children who ate fruits daily than in those who did not. These results suggest that children's salt intake can be influenced by their family members and that mothers should provide fruits instead of other types of snacks to their children.

Owing to the recent increase in the consumption of processed foods, salt intake is considered to be dependent on the amount of salt added by manufacturers rather than that added during cooking or at the table. Indeed, salt intake from processed foods accounts for approximately $80 \%$ of the total salt intake in developed countries. ${ }^{22}$ Thus, it is obviously important to approach food manufacturers to reduce the salt content of processed food, just as it is important to educate parents to be aware of their children's—and their own — salt intake.

The limitation of the present study is that the method to estimate daily salt intake by measuring sodium concentrations of the firstmorning urine has not been validated. As we have not collected 24-h urine samples or obtained dietary records from the participants, we estimated the salt intake by assuming urinary creatinine excretion to be $300 \mathrm{mg}$ per day. Obviously, further studies are required to validate this method of estimating daily salt intake.

In conclusion, the 3-year-old Japanese children in this study demonstrated high salt intake, and a significant number of them consumed excessive salt. As the presence of older siblings and the dietary habit of eating daily snacks or fruits influenced the children's sodium and potassium intake, it is important to educate the parents to encourage salt restriction for their children.

\section{CONFLICT OF INTEREST}

The authors declare no conflict of interest.

\section{ACKNOWLEDGEMENTS}

This study was supported in part by the Intramural Research Fund of the National Cerebral and Cardiovascular Center (22-4-5). 
1 Miura K, Okuda N, Turin TC, Takashima N, Nakagawa H, Nakamura K, Yoshita K, Okayama $\mathrm{A}$, Ueshima $\mathrm{H}$. Dietary salt intake and blood pressure in a representative Japanese population: baseline analyses of NIPPON DATA80. J Epidemiol 2010; 20: S524-S530.

2 Cailar G, Ribstein J, Mimran A. Dietary sodium and target organ damage in essential hypertension. Am J Hypertens 2002; 15: 222-229.

3 Antonios TF, MacGregor GA. Salt intake: potential deleterious effects excluding blood pressure. J Hum Hypertens 1995; 9: 511-515.

4 Altschul AM, Grommet JK. Food choices for lowering sodium intake. Hypertension 1982; 4: III116-III120.

5 Wardener HE, MacGregor GA. Harmful effects of dietary salt in addition to hypertension. J Hum Hypertens 2002; 16: 213-223.

6 Nagata C, Takatsuka N, Shimizu N, Shimizu H. Sodium intake and risk of death from stroke in Japanese men and women. Stroke 2004; 35: 1543-1547.

7 Shikata K, Kiyohara Y, Kubo M, Yonemoto K, Ninomiya T, Shirota T, Tanizaki Y, Doi Y, Tanaka K, Oishi Y, Matsumoto T, lida M. A prospective study of dietary salt intake and gastric cancer incidence in a defined Japanese population: the Hisayama study. Int. J. Cancer 2006; 119: 196-201.

8 Tsugane S, Sasazuki S, Kobayashi M, Sasaki S. Salt and salted food intake and subsequent risk of gastric cancer among middle-aged Japanese men and women. $\mathrm{Br} \mathrm{J}$ Cancer 2004; 90: 128-134.

9 Ministry of Health, Labour and Welfare, Japan. The National Nutrition Survey in Japan. 2007. http://www.mhlw.go.jp/houdou/2008/12/h1225-5.html.

10 The Japanese Society of Hypertension Committee for Guidelines for the Management of Hypertension. The Japanese Society of Hypertension Guidelines for the Management of Hypertension (JSH 2009). Hypertens Res 2009; 32: 3-107.

11 Ohta Y, Tsuchihashi T, Ueno M, Kajioka T, Onaka U, Tominaga M, Eto K. Relationship between the awareness of salt restriction and the actual salt intake in hypertensive patients. Hypertens Res 2004; 27: 243-246.
12 Ohta Y, Tsuchihashi T, Onaka U, Eto K, Tominaga M, Ueno M. Long-term compliance with salt restriction in Japanese hypertensive patients. Hypertens Res 2005; 28 : 953-957.

13 Haga M, Sakata T. Estimation of overnight urine volume and 24-h urine volume in healthy Japanese infants. J Jpn Soc Nutr Food Sci 2007; 60: 213-220 (in Japanese with English abstract).

14 He FJ, Marrero NM, MacGregor GA. Salt and blood pressure in children and adolescents. J Hum Hypertens 2008; 22: 4-11.

15 He FJ, MacGregor GA. Importance of salt in determining blood pressure in children. Hypertension 2006; 48: 861-869.

16 Hofman A, Hazebroek A, Valkenburg HA. A randomized trial of sodium intake and blood pressure in newborn infants. JAMA 1983; 250: 370-373.

17 Geleijnse JM, Hofman A, Witteman JCM, Hazebroek AAJM, Valkenburg HA, Grobbee DE. Long-term effects of neonatal sodium restriction on blood pressure. Hypertension 1996; 29: 913-917.

18 Simons-Morton DG, Obarzanek E. Diet and blood pressure in children and adolescents. Pediatr Nephrol 1997; 11: 244-249.

19 Cooper R, Soltero I, Liu K, Berkson D, Levinson S, Stamler J. The association between urinary sodium excretion and blood pressure in children. Circulation 1980; 62: 97-104.

20 Kawano Y, Ando K, Matsuura H, Tsuchihashi T, Fujita T, Ueshima H. Report of the Working Group for Dietary Salt Reduction of the Japanese Society of Hypertension: (1) Rationale for salt restriction and salt-restriction target level for the management of hypertension. Hypertens Res 2007; 30: 879-886.

21 Ministry of Health, Labour and Welfare, Japan. Dietary Reference Intakes for Japanese. Ministry of Health, Labour and Welfare, Japan: Tokyo, 2010, pp. 189-217 (2009, in Japanese).

$22 \mathrm{He}$ FJ, MacGregor GA. A comprehensive review on salt and health and current experience of worldwide salt reduction programmes. J Hum Hypertens 2009; 23: 363-384. 